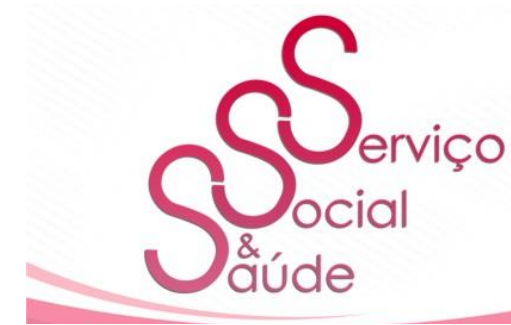

ISSN 2446-5992

(c) (1) (3)

doi: 10.20396/sss.v19i0.8661050

\title{
A demanda no processo de trabalho dos assistentes sociais e sua configuração em serviços de saúde
}

Demand in the work process of social workers and their configuration in health services

\author{
Francielle Lopes Alves ${ }^{1}$ \\ Regina Célia Tamaso Mioto ${ }^{2}$
}

\section{RESUMO}

$\mathrm{O}$ artigo tem o objetivo de discutir a demanda como um processo fundamental para a definição do trabalho dos assistentes sociais, especialmente nos contextos institucionais e multidisciplinares. A partir da área da saúde concentra sua atenção na análise da configuração da demanda de profissionais da saúde ao assistente social. Esta análise está precedida pelo debate da demanda como um processo que contém alguns pressupostos chaves. A análise trata dos aspectos da presença do "social" na processualidade da demanda, que se expressa através do "caso social". Tal debate se compromete a oferecer referenciais sobre a disposição do trabalho coletivo que são cruciais para estabelecer diálogos sobre a forma dos assistentes sociais enfrentarem os desafios do cotidiano para firmar seu projeto profissional.

Palavras-chave: Demanda Social. Serviços de Saúde. Serviço Social.

\begin{abstract}
The article has the objective to discuss demand as a fundamental process for defining the work of social workers, especially in institutional and multidisciplinary contexts. From the health area, focuses his attention on analyzing the configuration of the demand for health professionals to the social worker. This analysis is preceded by the demand debate as a process that contains some key assumptions. The analysis deals with aspects of the presence of the "social" in the processuality of the demand, which is expressed through the "social case". Such a debate is committed to offering references on the disposition of collective work that are crucial to establish dialogues on the way social workers face the daily challenges to establish their professional project.
\end{abstract}

Keywords: Social Demand, Health Services, Social Work.

\footnotetext{
${ }^{1}$ Assistente Social do Hospital Universitário da UFSC (HU/UFSC) e Preceptora do Programa de Residência Integrada Multiprofissional do HU/UFSC. Mestre e Doutora em Serviço Social pela Universidade Federal de Santa Catarina (UFSC). Telefone: 5548 3721-9127. E-mail: francialves@ hotmail.com.

${ }^{2}$ Assistente Social, professora do Programa de Pós-Graduação em Serviço Social da Universidade Federal de Santa Catarina (UFSC), membro do Núcleo de Pesquisa Interdisciplinar Sociedade, Família e Política Social (NISFAPS), bolsista de produtividade em pesquisa 1 do CNPq. E-mail: regina.mioto@gmail.com.
} 


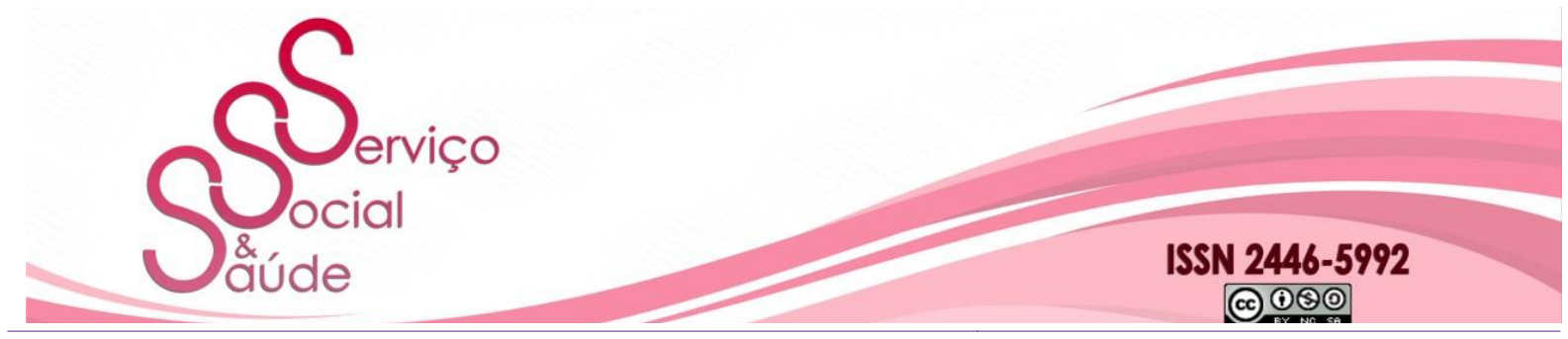

doi: 10.20396/sss.v19i0.8661050

\section{INTRODUÇÃO}

A peculiaridade do momento que vivemos, marcada tanto por uma crise social, política, cultural e econômica, como por uma crise sanitária sem precedentes, tem imposto inusitados desafios aos profissionais que atuam no campo da política social e particularmente para os assistentes sociais. Trata-se de uma conjuntura que desafia a enfrentar a precarização e intensificação do trabalho associadas às políticas de austeridade que tornam os recursos públicos cada vez mais escassos e a lógica dos direitos sociais cada vez mais ameaçada. Se constituem condições excepcionais de trabalho geradas pela pandemia que inclui medidas de distanciamento e proteção entre usuários e profissionais, demandas que requerem modalidades operativas cada vez mais flexíveis e personalizadas e também muita ansiedade em torno do aumento da incerteza acerca do encaminhamento e dos resultados das ações profissionais. Em termos gerais, trata-se de um momento que não só traz novas e insólitas exigências para todos/as nós, como escancara a forma como construímos a sociabilidade contemporânea brasileira, ancorada na sua histórica desigualdade estrutural e revela os descaminhos que o Brasil vem trilhando em relação à proteção social, especialmente a partir de 2016.

Por tudo isso, a peculiaridade desse momento nos impõe também a urgência de aprofundar o conhecimento sobre as requisições dirigidas aos assistentes sociais pela política social e como essas requisições se configuram no campo das instituições e dos serviços sociais. Conhecimento esse que está associado à defesa dos direitos sociais como o único caminho capaz, no contexto das sociedades capitalistas, de augurar uma sociedade mais protetiva e menos desigual. Historicamente, o direito imprimiu viabilidade às sociedades capitalistas a partir de uma ideia de igualdade entre os indivíduos. Esse credo, apesar das contradições inerentes ao capitalismo, permitiu que as sociedades se tornassem relativamente estáveis, à medida que os direitos se assentam sob a égide da solidariedade, como critério de ação de um Estado que se deve fazer democrático para conciliar suas ambiguidades 


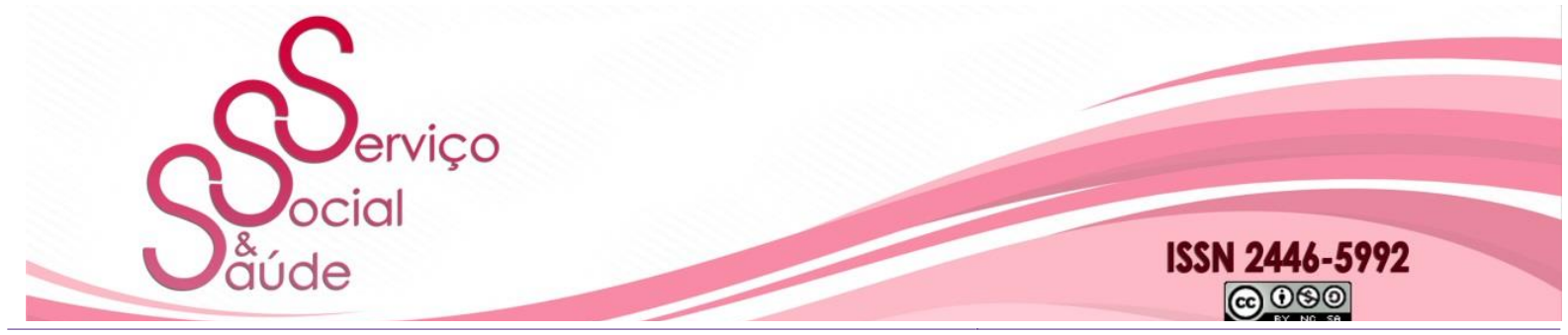

doi: 10.20396/sss.v19i0.8661050

3

(DONZELOT, 2007; ALVES, 2018). Assentam-se também na perspectiva de atendimento das necessidades humanas, que se tornaram também critério para sustentar decisões de diversas naturezas, sejam políticas, econômicas, culturais e jurídicas.

Na linha de análise de Nogueira (2002), referindo-se ao papel do Estado frente às necessidades de saúde, a autora afirma que as formas de atendimento às necessidades de saúde firmados a partir do papel do Estado "são construções que decorrem de escolhas individuais e coletivas, contendo um arcabouço técnico-teórico, que inclui olhares e perspectivas diversas, justamente o que lhes confere um sentido de opções políticas" (2002, p. 273), Porém, não são configurações despidas de interesses. “Traduzem um ideário que condiz com as agendas dos sujeitos políticos, influenciando e sendo influenciados pelas respectivas comunidades epistêmicas" (op. cit., p. 273).

Nesse sentido os direitos sociais se colocam estrategicamente nas inter-relações que compõem o processo social hegemônico e mantêm-se no bojo dos constantes movimentos presentes nos espaços institucionais de forma permanentemente atualizadas. Logicamente, esses movimentos são afetados pelos ciclos de reestruturação do capital que afetam as diferentes esferas da realidade social, tais como econômico-trabalhista, sociocultural, territorial, familiar e de gênero, simbólico-cultural. Isso explica a forte retomada do pensamento liberal a partir dos anos de 1990 no Brasil, à revelia das proposições da Constituição de 1988 e em direção a afirmação do absenteísmo do Estado em prol das prioridades na reprodução do capital. Nesse processo, a solidariedade social e a atenção às necessidades humanas são sobrepujadas pela lógica mercantil, fazendo com que a pobreza e a escassez de recursos tornem-se canais de um deslocamento radical de sentido sobre o direito. (ADELANTADO; GOMÀ, 2000; NOGUEIRA, 2002, p. 92).

Nesse contexto, com os agravos da crise sanitária que escancara as desigualdades e a falência da lógica mercantil para o atendimento das necessidades humanas, é que o presente artigo pretende jogar luzes sobre uma questão, que tem peso significativo na definição das ações dos assistentes sociais nos espaços institucionais - a demanda social. Trata-se de uma 


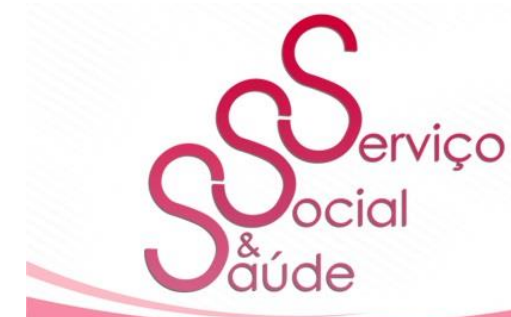

ISSN 2446-5992

(c) (1) (2)

doi: $10.20396 /$ sss.v19i0.8661050

4

construção pautada na busca pelo desvelamento dos processos contidos nas requisições realizadas ao Serviço Social no âmbito dos serviços sociais. Acreditamos que uma compreensão mais acurada desses processos pode contribuir significativamente para maior qualificação das respostas profissionais, para a asseveração da especificidade e da relativa autonomia profissional, bem como para a reafirmação cotidiana dos direitos sociais.

A discussão proposta se faz a partir do trabalho em saúde que, historicamente no Brasil tem uma forte institucionalização e responde às políticas públicas de saúde. Estas têm grande influência na qualidade e quantidade de recursos humanos presentes nos serviços de saúde, que a partir de seus objetivos e características definem quais profissionais irão compor as equipes. No entanto, de acordo com Peduzzi (1998) à medida que as políticas propõem a atenção integral às necessidades de saúde dos usuários dos serviços elas também se moldam às possibilidades de organização do trabalho no coletivo. Nessa direção Alves (2018) afirma que

[...] a incorporação de diferentes profissionais é dinamizada no campo das políticas públicas a partir do conjunto das relações e processos de elaboração que pesam critérios, interesses, pressões corporativas, expectativas e uma interlocução (difícil de mensurar e qualificar) com as experiências dos serviços e sua capacidade de tornar exequíveis as exigências postas no âmbito legal (2018, p. 286).

Contudo, a autora acrescenta que os serviços ao incorporarem os profissionais, via políticas públicas, mantém também sob controle os saberes e práticas que se envolverão na atenção às necessidades de saúde da população.

Diante dessas considerações introdutórias o artigo tem o objetivo de discutir a demanda como um processo fundamental para a definição do trabalho dos assistentes sociais, especialmente nos contextos institucionais e multidisciplinares. Para tanto, tendo como referência a área da saúde, particularmente serviços especializados, concentrará sua atenção na análise da configuração da demanda de profissionais da saúde ao assistente social. Esta análise está precedida pelo debate da demanda como um processo que contém alguns

\begin{tabular}{|l|l|l|l|l|l|}
\hline Serv. Soc. \& Saúde & Campinas, SP & v. 19 & $1-17$ & e020001 & e-ISSN 2446-5992
\end{tabular}




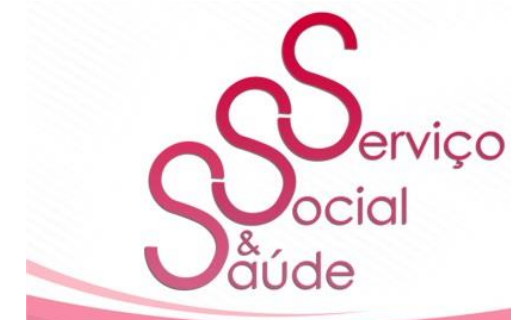

ISSN 2446-5992

(c) (1)(2)

doi: 10.20396/sss.v19i0.8661050

pressupostos chaves e sucedida pela indicação da presença do "social" na processualidade da demanda, que tem como uma relevante expressão o "caso social". Em seguida algumas considerações finais.

\section{A DEMANDA COMO PROCESSO: PRESSUPOSTOS PARA O DEBATE}

No Serviço Social existe uma compreensão das demandas profissionais bastante difundida que a encadeia a dinâmica das políticas sociais e às questões inerentes ao processo de constituição do direito à saúde, se nos alicerçarmos nesse campo. Tal posição implica reconhecer a imbricada composição de conflitos, protagonistas e interesses em cena (NETTO, 1996; MIOTO; NOGUEIRA, 2013). Nesse processo são definidas as suas características e suas particularidades no âmbito do Serviço Social ancoradas em alguns pressupostos que as antecedem. A primeira está relacionada à natureza da inscrição do Serviço Social como profissão na formação social capitalista. Especificamente no caráter contraditório do seu esquema de sobrevivência, indicando que para além de uma contradição que forjou a constituição sócio-histórica do Serviço Social, ela se mantém e se reatualiza como tônica das relações em contextos particulares. Isso ocorre principalmente nos espaços institucionais e expressam como o processo hegemônico atravessa as práticas profissionais que compreendem uma complexa relação entre visões de mundo, relações de poder, estratégias, interesses, articulações, enfrentamentos, tomadas de decisões nos espaços de trabalho dos assistentes sociais.

Um segundo pressuposto consiste em reconhecer que "demanda" é um conceito articulador na produção de conhecimento do Serviço Social e no cotidiano das assistentes sociais. Com isso, com frequência é possível observar que é empregado de forma dinâmica: pode designar a própria matéria-objeto de intervenção do assistente social (a violência, o desemprego, a pobreza, por exemplo), mas, por outro lado, pode indicar as práticas de requisição (sociais, institucionais e interprofissionais) de trabalho do assistente social nos diferentes espaços de atuação. Mas por que esse entrecruzamento pode acontecer? É possível 


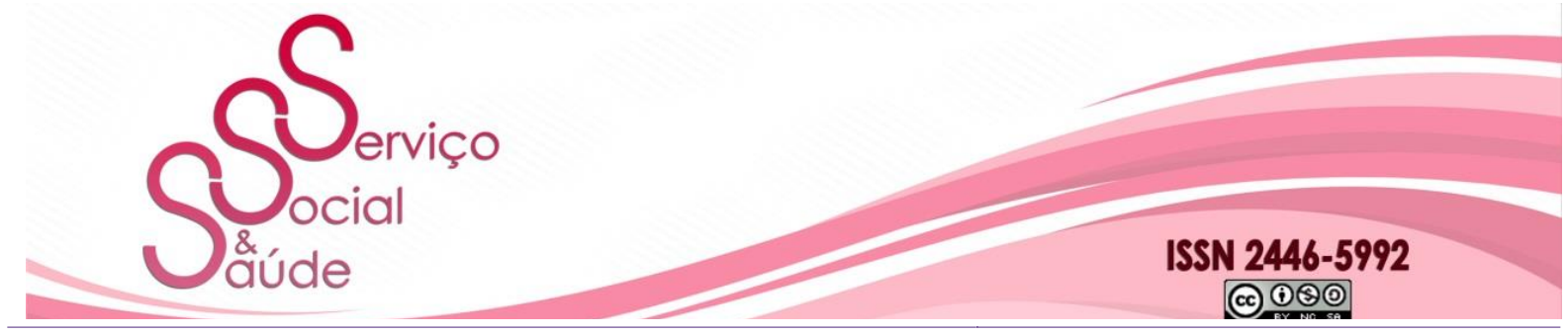

doi: 10.20396/sss.v19i0.8661050

indicar que há uma relação muito imbricada entre o reconhecimento da necessidade da atuação, sobre o que se deve atuar e as práticas de requisições que se constituem. Entretanto, se tomada no seu significado, a palavra se vincularia mais ao que chamamos de práticas que requisição do trabalho. De todo modo, matéria de intervenção e práticas de requisições profissionais são compreendidas como expressões de um processo indissociável, marcadas pelo reconhecimento da capacidade dos profissionais de atender e agir sobre certas necessidades.

Tomada nessa direção, um terceiro pressuposto sobre demanda é compreender que as condições e formas de organização do trabalho condicionam um campo de possibilidades para sua constituição. Ou seja, é preciso considerar as condições e estrutura de trabalho do assistente social, mas também dos profissionais que podem compor as equipes e serviços na configuração da demanda. São alguns exemplos de fatores importantes: a presença ou a disponibilidade do profissional na equipe, visto que a participação direta do profissional nesse conjunto leva-o a ser incorporado nas diferentes dimensões da atenção às necessidades apresentadas pelos usuários em um serviço; a possibilidade de tempo de trabalho exclusivo na equipe e inclusive a permanência no mesmo espaço; a situação de trabalho do profissional potencialmente demandante, que tende se ater às questões específicas de sua área em situações de sobrecarga de trabalho ou aplicar práticas de seleção das situações que vai demandar o assistente social; a viabilidade e circunstâncias que permitam o encontro e o diálogo, pois é assim que se pode gerar e redistribuir demandas de atuação no processo de acompanhamento dos usuários.

O quarto pressuposto refere-se à relação contraditória que se estabelece entre as demandas, enquanto práticas de requerimento e enquanto matéria-objeto da profissão. De acordo com Alves (2018, p. 61), as demandas enquanto práticas de requerimento estão vinculadas às requisições postas pelo processo de divisão sócio-técnica do trabalho e estão condicionadas também à visão, ou ao recorte, que os demandantes do trabalho dos assistentes sociais fazem sobre o que é o "social”. Isso porque há uma forte relação entre a prática dos 


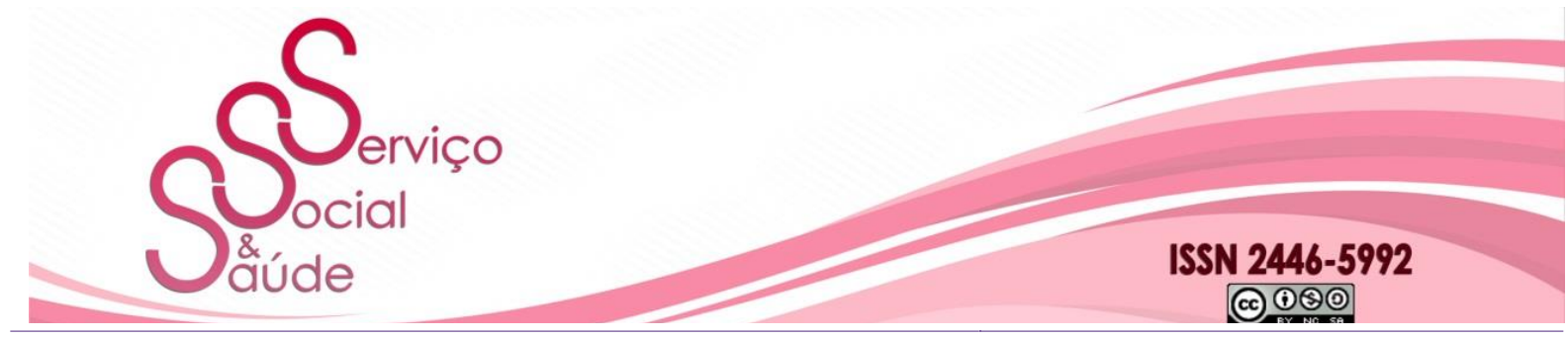

doi: 10.20396/sss.v19i0.8661050

7

assistentes sociais em saúde o "social”, "abarcado para emissão de juízos/avaliações não restritos ao Serviço Social e, muitas vezes, subsidiam uma arbitragem para o acesso e uso dos serviços de saúde, assim como para demandar a atuação do assistente social”.

Isso significa que não há processo de demanda sem que haja uma projeção sobre o que deverá incidir a ação. Inclusive, geralmente existem acertos formais e informais nos contextos institucionais sobre uma determinada projeção do social. Considerando que os assistentes sociais estão inseridos em processos coletivos de trabalho, particularmente em equipes multiprofissionais há, de acordo com Merhy (2002), na relação com a matéria dos assistentes sociais, tomada como "social", uma apreensão processada a partir das tecnologias que são próprias de cada profissional/área demandante. Por exemplo, na área da saúde, os profissionais das diferentes especialidades reconhecem as necessidades de saúde apresentadas pelos usuários dos serviços a partir de um determinado recorte de objeto sob o qual se aplicam simultaneamente conhecimentos, técnicas, valores, traduzidos à especificidade do "caso".

Sem a presença do assistente social, as questões do "social" tendem a ser apreendidas sob recortes dos quais não participa da definição ou não ajuda a estabelecer. A presença do assistente social recompõe esse campo que envolve arbitragens, o que facilita ou tensiona a fluência das práticas. É presente no serviço, a partir da experiência, que o assistente social expressará a matéria ao modo que elabora/aborda, não se prendendo às matérias definidas por terceiros. Os limites de permanência, geralmente associados a precarização das relações de contrato e de trabalho, pode explicar a falta de identificação do assistente social com aquilo que é demandado, pois perde-se o espaço do diálogo e dos enfrentamentos necessários que reponham objetos, competências e atribuições na direção do projeto desenvolvido pelo profissional. Ademais, considerando os demais profissionais que podem compor uma equipe, a experiência do trabalho é fundamental para uma apreensão sobre o Serviço Social e o trabalho com o assistente social.

As demandas constituídas a partir da matéria-objeto são aquelas definidas pelos assistentes sociais para si em um projeto profissional emergente. Especificamente, trata-se

\begin{tabular}{l|l|l|l|l|l}
\hline Serv. Soc. \& Saúde & Campinas, SP & v. 19 & $1-17$ & e020001 & e-ISSN 2446-5992 \\
\hline
\end{tabular}




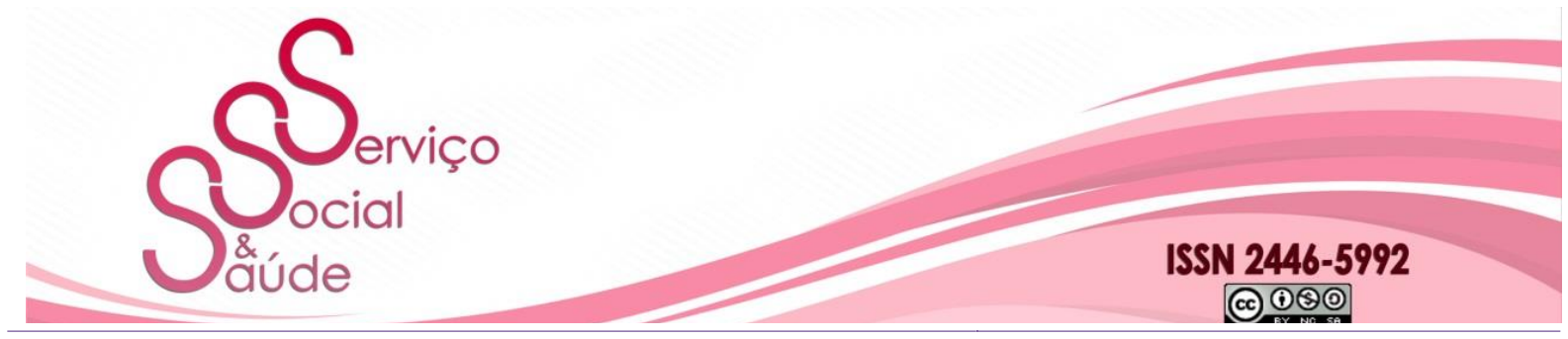

doi: 10.20396/sss.v19i0.8661050

aqui do projeto ético-político profissional construído pelo Serviço Social brasileiro. Para Netto (2005), o projeto profissional consiste numa estrutura dinâmica que se transforma a partir de modificações referentes ao quadro: de necessidades sociais com as quais a profissão opera; das transformações sociais, econômicas, culturais que ocorrem nos diferentes momentos históricos; e das alterações decorrentes do próprio processo de desenvolvimento da profissão. Assim, a dimensão política lhe é inerente e está diretamente relacionada aos projetos societários presentes e em disputa em um determinado momento histórico.

Com isso, o processo de análise das demandas é fundamental para a construção das respostas profissionais, uma vez que estas se constroem numa constante tensão entre a reprodução de um universo de respostas tradicionalmente organizadas no campo da política social/instituições, com inovações, para responder aos dilemas das necessidades da população, havendo dessa forma a incorporação controlada das diferentes especialidades e respostas alternativas ancoradas no projeto profissional emergente.-

\section{A CONFIGURAÇÃo dA DEMANdA DE PROFissionais da SAÚde AO ASSISTENTE SOCIAL}

A demanda se configura no contexto de equipes de saúde em torno de uma ideia do "social", algo aprimorado ao longo do tempo de inserção do profisssional no serviço. Mas por onde caminha essa apreensão do objeto, essa projeção do social?

Pesquisa realizada por Alves (2018) em três serviços operacionalizados em um hospital geral permitiu indicar que nessa apreensão é muito presente uma avaliação da situação sociofamiliar do usuário. Esta se processa através de um conjunto das atividades desenvolvidas pela equipe de profissionais, como a aplicação de entrevistas, anamneses ou instrumentos que cumpram a função de obter um panorama da situação de saúde-doença do usuário.

A partir desse panorama que descortina um universo amplo de dificuldades para 


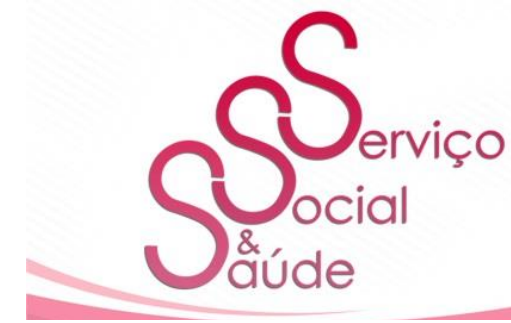

ISSN 2446-5992

(c) (1) (3)

doi: $10.20396 /$ sss.v19i0.8661050

realização do tratamento admite-se que é sobre um universo amplo de dificuldades, de relações "desqualificadas", de certos comportamentos, que se recorta ou define-se o "social". Entretanto, a construção do referido panorama também é uma forma de desenvolver vínculo e buscar ampliar o olhar às necessidades ou questões apresentadas pelo usuário ou família. Esse "social” é, portanto, uma matéria multifacetada e em constante dimensionamento.

O "social" conforma-se como uma matéria que circula heterogeneamente entre os profissionais para definir ações e que é apreendido nos espaços de atuação, tornando-se um referencial dado pelas práticas instituídas nos serviços e nas equipes. É muitas vezes uma relação com um conjunto de conhecimentos sobre a vida dos sujeitos que precisa vir à tona, pois a partir dela se definirá o tratamento médico, por exemplo. Isso é bastante presente em serviços de transplante de órgãos no Brasil, por exemplo. Nesse caso, o "social" é colocado como algo previsto de ser avaliado com respaldo legal, o que não se localiza claramente nas legislações que orientam a organização dos serviços ${ }^{3}$.

Portanto, é na experiência dos serviços que se constrói uma legitimidade para a incursão sobre o "social", que tem um status no campo da etiologia. Está presente na análise e nas decisões e estratégias que envolvem os diagnósticos. Historicamente os fatores socioeconômicos precisam ser perquiridos nos serviços de saúde para construção do diagnóstico, assim como para orientar o manejo do tratamento. Entende-se que esse levantamento pode ser limitado e o atendimento de outros profissionais (assistentes sociais e psicólogos) necessário para levantar informações complementares.

A avaliação de riscos é algo que permeia toda a prática de exames. A análise da etiologia, que engloba a identificação das causas do adoecimento, estará disposta a olhar fatores sociais que levam a esse desfecho. Muitas vezes, está presente não somente nos corpos ou nas queixas não proferidas, mas nos comportamentos, na qualidade das relações, como as

\footnotetext{
3 Alves (2018) verificou que em um serviço de transplante hepático, os profissionais que integram a equipe compreendem que a avaliação sociofamiliar estaria localizada em um protocolo previsto nas orientações legais do serviço, embora não esteja prevista no texto das portarias ministeriais pesquisadas. Indica que os profissionais de todas as áreas que compõem o serviço demandam atendimento do assistente social para o que se refere à organização e estrutura da família para o cuidado domiciliar e para as condições de acesso ao próprio serviço.

\begin{tabular}{|l|l|l|l|l|l|}
\hline Serv. Soc. \& Saúde & Campinas, SP & v. 19 & $1-17$ & e020001 & e-ISSN 2446-5992
\end{tabular}
} 


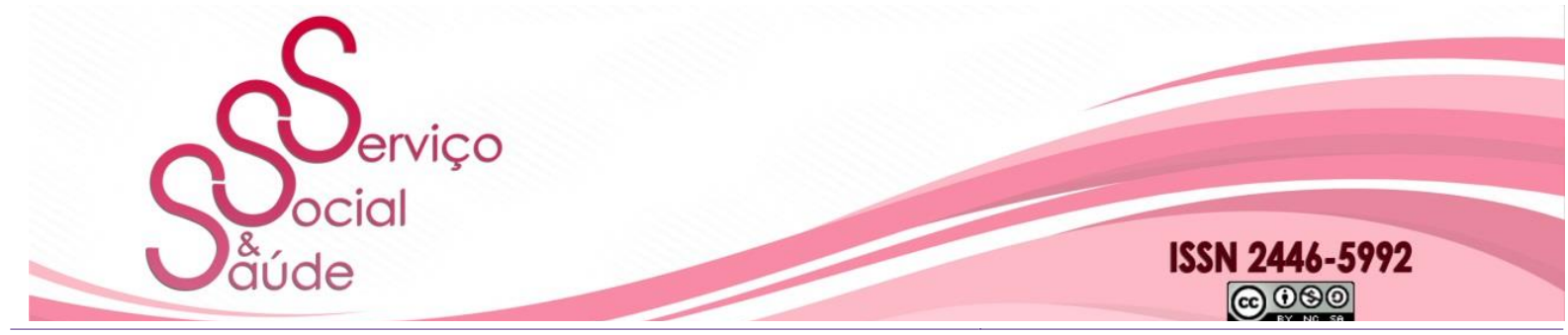

doi: $10.20396 /$ sss.v19i0.8661050

brigas entre usuários e acompanhantes no hospital, nas presenças ou ausências dos genitores, nos discursos desencontrados ao se investigar o adoecimento. Para isso, a experiência é válida e comumente sintetizada na ideia de feeling.

O levantamento de dados-indicadores se associa a algumas práticas de seleção e pressupostos estabelecidos pelos profissionais. Destaca-se na "seleção" para demandar o atendimento do assistente social a pessoa pertencer a determinados grupos/segmentos sociais vulneráveis ou considerados "de risco", como pessoas em situação de rua, pessoas sem identificação, idosos e crianças/adolescentes sem acompanhante, usuários de álcool e drogas ilícitas, pessoas vítimas de violências.

Portanto, não há como falar em demanda de atuação profissional sem falar de processos de trabalho em conexão. As tecnologias mediam o processo dos recortes de objetos de intervenção que perpassam a demanda. Nessa direção, expressando as tecnologias, é importante reconhecer o papel do Histórico de Enfermagem, do Acolhimento com Classificação de Risco, da Passagem de Plantão, dos históricos aplicados pelas diferentes áreas, dos exames físicos e do Estudo Social, no caso dos assistentes sociais - e mesmo da teoria das Necessidades Humanas Básicas (teoria norteadora para a assistência sistematizada em Enfermagem) e da clínica (em se tratando da Medicina), por exemplo.

A clínica será referência nessa relação. Ela alcançou uma dominação simbólica de saberes técnicos em saúde. Inaugurou o indivíduo/paciente como objeto de observação sistemática pela leitura diferencial dos casos (FOUCAULT, 1977). Exame e interrogatório do paciente e raciocínio clínico para o diagnóstico confiável serão espelhos para outras profissões. A semiologia médica é referência para a organização das práticas que emergiram com o passar do tempo na saúde.

É preciso ressaltar que no processo de demanda ainda perdura uma convergência entre fatores etiológicos e um discurso que avança para uma vigilância acerca das responsabilidades e capacidades dos indivíduos e famílias nas situações de vulnerabilidade e risco social, como nos primórdios da inserção dos assistentes sociais na saúde. A racionalidade clínica se coloca \begin{tabular}{|l|l|l|l|l|l|}
\hline Serv. Soc. \& Saúde & Campinas, SP & v. 19 & $1-17$ & e020001 & e-ISSN 2446-5992
\end{tabular} 


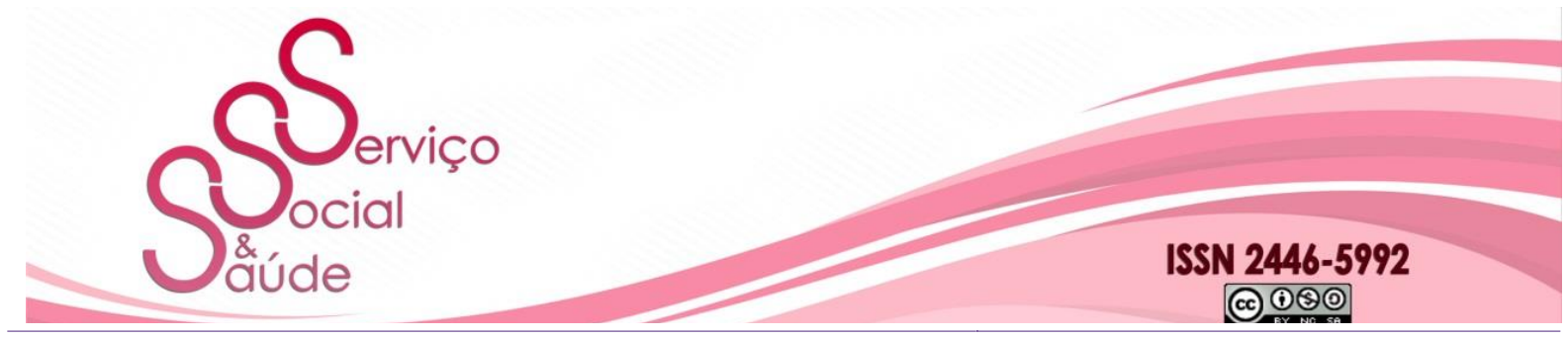

doi: 10.20396/sss.v19i0.8661050

acerca do "social", cumprindo sua função de ser ferramenta para classificar interconexões entre os fatos e perceber as hipóteses (FREIDSON, 2009). Num olhar sobre os fatores etiológicos, pode-se, muitas vezes, identificá-los com um discurso "biografizador" (CERCHIARO, 2008), em que indivíduos e famílias podem ser responsabilizados ou são responsáveis pela situação e pela solução dos problemas vivenciados. Com as limitações do raciocínio clínico tradicional, os serviços de saúde tendem a permanecer nessa lógica: na variedade de controles e intervenções reguladoras do bem-estar, de algum modo correspondendo ao passado, às políticas de controle das populações afetadas pela pobreza.

\section{NA PROCESSUALIDADE DA DEMANDA O "SOCIAL" COMO DIAGNÓSTICO: O "CASO SOCIAL"}

Considerar as práticas, as tecnologias, os referenciais para uma aproximação ao processo de demanda deixam evidente que nele é incontornável tratar da questão da rotina nos serviços. Como descreve Alves (2018), as práticas rotinizadas são forças com grande significado e positivamente valorizadas nos serviços de saúde. A rotina manifesta o sentido de um "passado", que se recrudesce no presente, geralmente garantindo a continuidade daquilo que é dominante, mas são também o "lugar" das disputas e da emergência do novo, tornando este um permanente campo de negociações.

Se particularizada a relação com a Medicina, pode-se observar que, numa relação tradicional, a demanda de atuação de outros profissionais ocorre geralmente a partir do caso, da situação singular. Contudo, uma particularidade dessa área é a tendência de que a demanda de atuação de outros profissionais seja um ato de prescrição de medidas da conduta terapêutica. Embora a relação hierarquizada no contexto de trabalho em equipes seja constantemente questionada em diversas dimensões, é possível apontar que ainda se preservam características da demanda como uma forma de prescrição. 


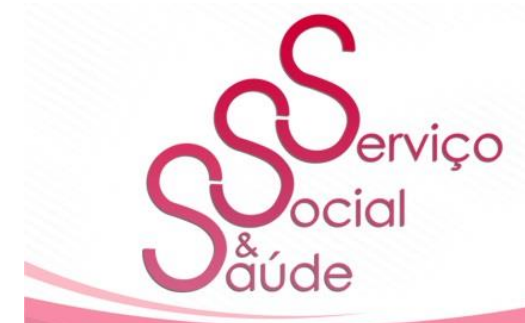

ISSN 2446-5992

(c) (1) (2)

doi: 10.20396/sss.v19i0.8661050

12

A demanda tipo-prescrição é aquela que contém diagnóstico e "terapêutica", ou seja, já chega para o assistente social apenas para execução. Seu “enfrentamento" pelos assistentes sociais no cotidiano geral expõe também as diferentes perspectivas de atendimento e "tratamento esperado". A demanda tipo-prescrição - geralmente alinhada à responsabilização das famílias no cuidado e atenção a seus membros, a comportamentos higiênicos, à alta agilizada, ao encaminhamento de "sujeitos desgarrados", por exemplo - remonta a questões da pauta da emergência da profissão na saúde, submetidas à lógica e à efetivação subsidiária do trabalho médico-previdenciário. A sua admissão como um especialista conferiu ao profissional um "status", porém a demanda é introjetada como processo que ocorre de acordo com critérios de um agente/profissional que esteja na linha de frente (em geral, o médico ou o enfermeiro).

Para as demandas de atuação dos profissionais que compõem as equipes, a Enfermagem é uma área que parece conciliar racionalidade clínica e uma espécie de autoridade adjunta (FREIDSON, 2009). O enfermeiro é quem mais demanda em comparação com outras áreas de atuação, mas também é o eventual substituto para um grande número de tarefas. Na pesquisa de Alves (2018) alguns profissionais confirmam que poderiam tentar atender à situação que gerou a demanda ao assistente social, o que não ocorreu por falta de um "pouquinho mais de conhecimentos".

Com relação a como as tecnologias ou instrumentos processam a demanda sobre o “social”, pode-se falar da construção do diagnóstico do "caso social". O social pode ser fator etiológico a ser considerado e tratado no contexto de uma doença, mas pode ser colocado no centro do processo das definições que culminam no diagnóstico.

O diagnóstico em si é uma categoria poderosa que cimenta uma visão particular da saúde-doença. Tanto que, até a década de 1970, o Serviço Social preocupava-se com a elaboração de diagnósticos e tipologias de diagnósticos como instrumental válido e seguro para atuação. Era a partir do diagnóstico que o assistente social identificaria o seu objeto de intervenção (VAISBICH, 1976). 


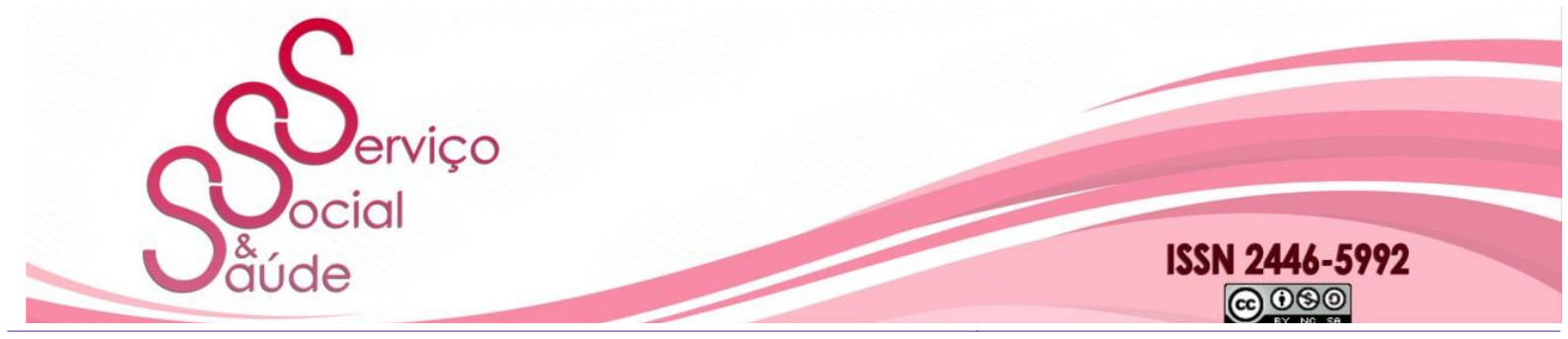

doi: 10.20396/sss.v19i0.8661050

O diagnóstico é o painel de consenso de especialistas. Uma vez atribuído aos indivíduos, o diagnóstico inicia seu trabalho classificatório e exerce suas funções sociais; categoriza as realidades da saúde de maneira tangível, determinando quem tem acesso a quais recursos, quem terá jurisdição na sua gestão. Mesmo na atualidade, quando se defende um papel mais ativo dos usuários junto aos serviços e na relação com os profissionais, o diagnóstico continua a ser um arbítrio central, conferindo uma autoridade jurisdicional significativa. Por isso, o diagnóstico se torna uma categoria e um processo que se ampliam, abrangendo mais do que a lesão patológica. É uma ferramenta analítica que serve como um prisma que reflete e lança luz sobre uma multiplicidade de problemas em saúde (JUTEL; NETTLETON, 2011).

O "caso social" pode ser considerado uma formulação diagnóstica e, como tal, pressupõe um processo, em que tem centralidade a situação sociofamiliar do usuário (não ter família é uma questão muito relevante em contextos de adoecimento e bastante problematizado por profissionais na área da saúde). O diagnóstico considera também os fatores sociais para o desenvolvimento de uma doença ou sua complicação e as condições do paciente ou de a família realizar o tratamento prescrito. O diagnóstico de "caso social" determina o acesso a recursos, como tratamentos, acesso a profissionais e internação. A disponibilidade do serviço na realização desse tratamento (geralmente, por meio da internação social) ocorre sob uma das principais coordenadas da prestação de assistência no setor social: a falha das redes primárias e/ou secundárias (CASTEL, 1998), a depender dos riscos e/ou da "carreira" do doente. A demanda de atuação do assistente social estará na terapêutica, muitas vezes prescrita desde a admissão do usuário e tenciona, geralmente, evitar a prescrição da internação.

Segundo Jutel e Nettleton (2011), os médicos são constantemente pressionados a promulgar um diagnóstico. Isso ocorre por forças administrativas, comerciais, profissionais, econômicas e mesmo pelos usuários. Nessa direção, no contínuo do "caso social", da “internação social” - porém, às vezes, independentemente deles -, está a "alta social”. A “alta 


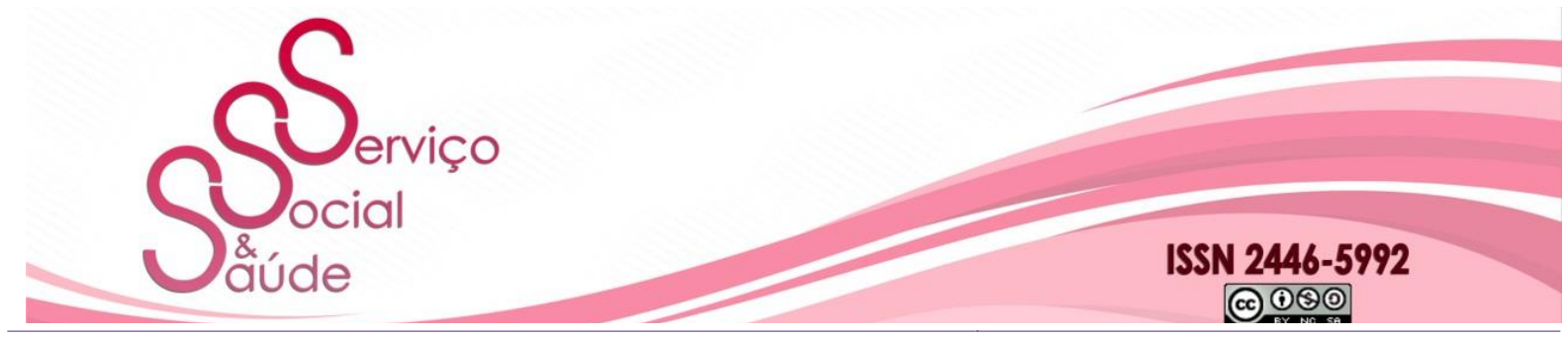

doi: $10.20396 /$ sss.v19i0.8661050

social" se refere às situações em que os usuários internados na unidade hospitalar encontramse aptos à alta clínica (alta médica), porém a situação sociofamiliar interfere no seu retorno ao domicílio e, mesmo, pela inexistência de um. O assistente social é demandado para propor soluções rápidas e eficazes que possibilitem o retorno do sujeito ao seu cotidiano (LEAL; XAVIER, 2015). É, portanto, o momento de se reconhecer a ordem negociada das fronteiras profissionais e das respostas organizacionais na provisão de cuidados (JUTEL; NETTLETON, 2011).

O social, no diagnóstico de "caso social", é aquele adjetivo que carrega diferentes sentidos (DONZELOT, 1980), que classifica um problema particular e crescente nos serviços de saúde. Colocam os assistentes sociais a construir propostas e enfrentamentos diante do lastro conservador que expressa.

\section{CONSIDERAÇÕES FINAIS}

A discussão das demandas (seja como forma fenomênica da matéria-objeto ou como práticas de requerimento de intervenção) no ponto de vista apresentado expõe tanto a importância da produção de conhecimento em Serviço social conectada às condições dos sujeitos/assistentes sociais nos processos e experiências em que se inserem, como se implica em oferecer referenciais sobre formas de disposição do trabalho coletivo que são cruciais para estabelecer diálogos sobre a forma dos assistentes sociais enfrentarem os desafios do cotidiano de acordo como seu projeto profissional. Embora hegemônico para o conjunto profissional, o projeto profissional na dimensão dos espaços ocupacionais situa-se contra hegemônico, daí emergirem diferentes desafios para as condições concretas de sua efetivação.

Enquanto as dimensões social e subjetiva no trabalho em saúde ainda são entendidas como algo que se atravessa na saúde e não como pertencentes à prática em saúde (FIGUEIREDO; FURLAN, 2008 apud WIESE, 2010), estamos falando de um elemento forte e abrangente que implica posicionamento profissional sintonizado com o projeto da profissão. 


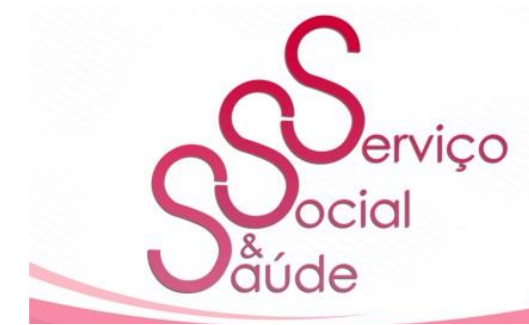

ISSN 2446-5992

(c) (1) (3)

doi: 10.20396/sss.v19i0.8661050

Também enquanto os profissionais tiverem receio que no seu cotidiano de trabalho surjam demandas sociais, pois não sabem como lidar com elas (WIESE, 2010), se incluirmos as implicações da des-organização dos serviços no contexto atual de pandemia, esse medo se potencializa. Frente a precarização das "forças" envolvidas nos serviços a tendência é de os assistentes sociais que estão na "linha de frente" estarem ainda mais constrangidos e pressionados diante dos dilemas precedentes que se intensificam, como a falta de investimentos públicos de toda ordem que culminam com níveis elevadíssimos de desproteção social.

Em se tratando do modelo hospitalocêntrico de enfrentamento da pandemia, é difícil falar em sucesso diante dos milhares de mortes até agora ocorridas, como afirma Merhy (2020). Em sua compreensão, a pandemia da Covid-19 colocou ao sistema de serviços de saúde o dilema de desenvolver a tecnologia de cuidado mais nobre da área: a tecnologia leve, que envolve a capacidade de encontrar, de oferecer alternativas, de pensar projetos de autocuidado. A disposição das pressões sugere um "social" que precisa estar ainda mais "sob controle" e submetido a eficácia dos serviços ou que, independente das contradições embutidas, simplesmente nem chegará a se constituir demanda diante das atuais possibilidades assistenciais.

Recebido em junho de 2020 - aprovado em junho de 2020

\section{REFERÊNCIAS}

ADELANTADO, J.; GOMÀ, R. El contexto: la reestructuración de los regímenes de bienestar europeos. In: ADELANTADO, J. (Org.). Cambios en el estado del bienestar: políticas sociales y desigualdades em España. Barcelona: Içaria/Antrzyt/Universitat Autônoma de Barcelona, 2000, p. 61-95.

ALVES, F. L. A configuração da demanda de atuação dos assistentes sociais em serviços de saúde: questões do 'social' como matéria-objeto de trabalho. 2018. 409 p. Tese 


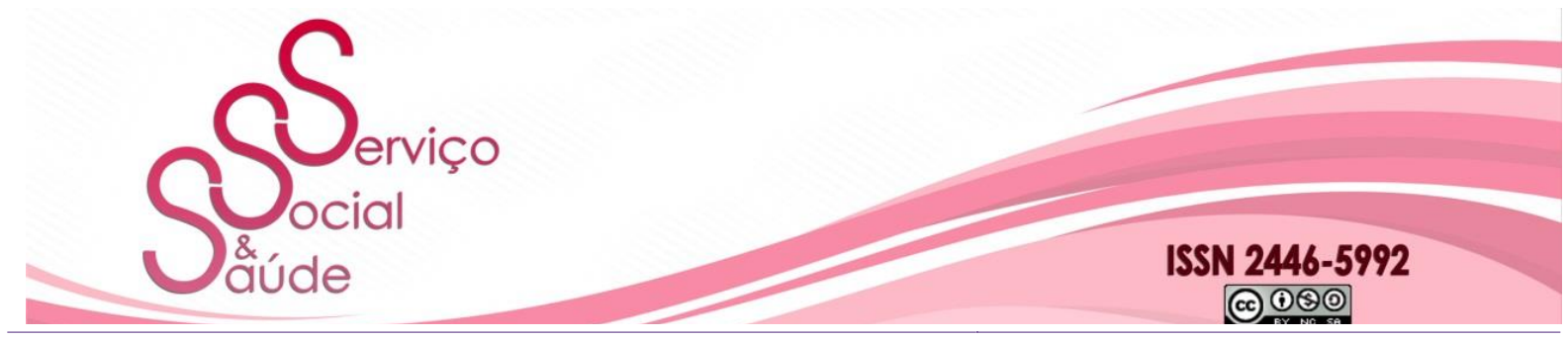

doi: 10.20396/sss.v19i0.8661050

(Doutorado) - Universidade Federal de Santa Catarina, Programa de Pós-Graduação em Serviço Social, Florianópolis, 2018. Disponível em: <http://www.bu.ufsc.br/teses/PGSS0202T.pdf>

CASTEL, R. As metamorfoses da questão social: uma crônica do salário. Petrópolis: Vozes, 1998.

CERCHIARO, E. O. El Servicio Social y los procesos de medicalización de la sociedad uruguaya en el período neobatllista. Montevideo: Ediciones Trilce, 2008.

DONZELOT, J. A polícia das famílias. Rio de Janeiro: Graal, 1980.

DONZELOT, J. La invención de lo social. Ensayo sobre la declinación de las pasiones políticas. Buenos Aires: Nueva Visión, 2007.

FOUCAULT, M. O nascimento da clínica. Rio de Janeiro: Forense-Universitária, 1977.

FREIDSON, E. Profissão médica: um estudo de sociologia do conhecimento aplicado. São Paulo/Porto Alegre: UNESP/SIMERS, 2009.

JUTEL, A.; NETTLETON, S. Towards a sociology of diagnosis: reflections and opportunities. Social Science \& Medicine, v. 73, n. 6, p. 793-800, set. 2011. Disponível em: <https://www.sciencedirect.com/science/article/pii/S0277953611004540?via\%3Dihub $>$.

Acesso em 16 jan 2018.

LEAL, R. A. S.; XAVIER, A. Alta hospitalar: a importância do trabalho multiprofissional e interdisciplinar em saúde. Trabalho de Conclusão de Curso (Residência Integrada Multiprofissional em Saúde - Área Urgência e Emergência). Universidade Federal de Santa Catarina, Florianópolis, 2015. Disponível em: <http://www.hu.ufsc.br/setores/servicosocial/wp-content/uploads/sites/17/2014/11/TCC-ROBERTA-SANTIN-LEAL.pdf>. Acesso em: jan. 2018.

MERHY, E. E. Saúde: a cartografia do trabalho vivo. 2 ed. São Paulo: Hucitec, 2002.

MERHY, E. E. Mesmo na derrota, falam de vitória. 2020. (8m37s). Disponível em:

\begin{tabular}{l|l|l|l|l|l}
\hline Serv. Soc. \& Saúde & Campinas, SP & v. 19 & $1-17$ & e020001 & e-ISSN 2446-5992 \\
\hline
\end{tabular}




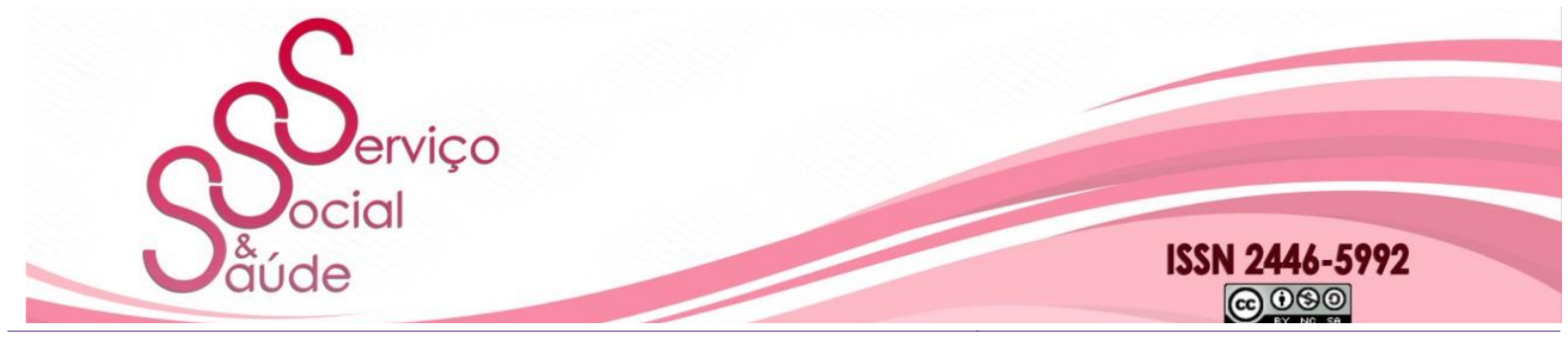

doi: 10.20396/sss.v19i0.8661050

https://www.youtube.com/watch?v=07YJ-oKgz0U. Acesso em 05 mai 2020.

MIOTO R. C. T.; NOGUEIRA, V. M. R. Política social e Serviço Social: os desafios da intervenção profissional. Katálysis, Florianópolis, v. 16, p. 61-71, 2013.

NETTO, J. P. Transformações societárias e Serviço Social: notas para uma análise prospectiva da profissão. Serviço Social \& Sociedade, São Paulo, n. 50, p. 87-132, 1996.

NETTO, J. P. La construcción del proyecto ético-político del Servicio Social frente a la crisis contemporánea. In BORGIANNI, E.; GUERRA, Y.; MONTAÑO, Carlos. (Org.). Servicio Social crítico: hacia la construcción del nuovo proyeto ético-político profesional. São Paulo: Cortez, 2005, p. 153-170.

NOGUEIRA, V. M. R. O direito à saúde na reforma do Estado brasileiro: construindo uma nova agenda. Tese (Doutorado em Enfermagem) - Universidade Federal de Santa Catarina, Florianópolis, 2002.

PEDUZZI, M. Equipe multiprofissional de saúde: a interface entre trabalho e interação. Tese (Saúde Coletiva) - Universidade Estadual de Campinas, Campinas, 1998.

VAISBICH, S. B. Serviço Social: tipologia de diagnóstico. Subsídios. São Paulo: Cortez \& Moraes, 1976.

WIESE, M. L. A categoria social no âmbito das práticas profissionais no Programa Saúde da Família do município de Blumenau. Dissertação (Mestrado em Serviço Social) Universidade Federal de Santa Catarina, Florianópolis, 2003. 